\title{
The use of budget impact analysis in the economic evaluation of new medicines in Australia, England, France and the United States: relationship to cost-effectiveness analysis and methodological challenges
}

\author{
Salah Ghabri ${ }^{1} \cdot$ Josephine Mauskopf $^{2}$
}

Received: 21 September 2017 / Accepted: 27 September 2017 / Published online: 14 October 2017

(C) Springer-Verlag GmbH Germany 2017

Keywords Health technology assessment · Budget impact analysis · Cost-effectiveness · Affordability · Budgetary sustainability

JEL Classification $\mathrm{I} 18 \cdot \mathrm{H} 68 \cdot \mathrm{C} 18$

\section{Introduction}

Good practices for budget impact analysis (BIA) have been increasingly developed since the year 2000 [1, 2]. As a financial approach, BIA is currently mandatory to support manufacturers' formulary submissions for national or provincial reimbursement in many countries (e.g. Canada, Belgium, Australia, and Poland). The objective of this editorial is to provide a better understanding of the current use of budget impact analysis in four countries: Australia, England, France and the United States of America (USA) and to stress the "common" decision maker concerns and methodological issues related to BIA across these countries.

\section{Role of BIA in the selected countries}

The role of BIA varies across the selected countries and reflects the differences in terms of clinical and

Salah Ghabri

s.ghabri@has-sante.fr

1 Department of Economic and Public Health Evaluation, French National Authority for Health (Haute Autorité de Santé, HAS), 5 Avenue du Stade de France, 93218 Saint-Denis La Plaine Cedex, France

2 RTI Health Solutions, RTI International, Research Triangle Park, NC, USA reimbursement decisions specific to French, English, Australian and American jurisdictions.

In Australia, the Pharmaceutical Benefits Advisory Committee (PBAC) [6] assesses whether a drug is both clinically effective and cost-effective before recommending its inclusion into the medicines list of the Pharmaceutical Benefits Scheme (PBS). PBAC provides detailed guidelines about how the budget impact should be estimated; in particular, BIA based on epidemiological and market shares data is described. Until 2010, the estimated budget impact each year over 4 years determined whether (only if $>$ A \$10 million in any of the first 4 years of product listing) PBAC's recommendations had to be approved by the cabinet of the federal government. Since 2010-2011, any recommendation by PBAC that has a financial impact for the federal government is considered by the cabinet [7]. Mauskopf et al. [8] showed that the estimated financial impact of a drug on the Australian drug budget is a significant predictor of the PBAC recommendation for reimbursement.

In England, reimbursement of new medicines is recommended by the National Institute for Health and Clinical Excellence (NICE) on the basis of effectiveness, safety, unmet need, and cost-effectiveness below a threshold value (CET). The National Health Service (NHS) institution in England and Wales has to provide funding for medicines with NICE positive recommendation. NICE has developed general guidelines for conducting BIA [9, 10]. After reimbursement recommendation by NICE, costing templates are created and provided to the regions to help them to estimate the likely budget impact of the reimbursement recommendation. Early this year, among other changes, NICE announced that a budget impact test will follow a positive recommendation for NHS reimbursement such that for drugs that are expected to cost the NHS more than $£ 20$ million in any one of their first 
3 years of use the NHS will be required to have discussions with the pharmaceutical company as to how to reduce the impact on the NHS (https://www.nice.org.uk/news/article/ nice-gets-go-ahead-to-fast-track-more-drug-approvals).

In France, the reimbursement decision is based on clinical effectiveness and not on cost-effectiveness outcomes. Clinical effectiveness and cost-effectiveness are assessed independently and in parallel by different committees. The French national authority for health (HAS), in giving its efficiency opinion, does not make recommendations about reimbursement. The economic evaluation is one among other criteria (e.g. added clinical benefit) that is used by the Pricing Committee (CEPS) for negotiating the price with the manufacturers [3]. Since January 2016, in addition to the cost-effectiveness analysis (CEA) submissions, BIAs are required as part of efficiency dossiers submitted by manufacturers for innovative drugs with an expected 2-year sales revenue above $50 €$ million. A new HAS guideline for BIAs has been recently developed $[4,5]$. The short time since the implementation of the BIA process has not allowed evaluation of how BIA results might be used in the process of price negotiation. Nevertheless, BIAs assessed by the HAS are helping public authorities to use better estimates of the budgetary impact in France in populations of interest (expected target and treated populations) during the phase of price negotiation.

Unlike in Australia, England and France, there is no public health technology assessment (HTA) agency who recommends coverage decision and pricing for new medicines in the USA. Prices for medicines are fixed at the discretion of manufacturers with an agreed percentage discount for public insurers. There are no specific guidelines for BIA. However, the Academy of Managed Care Pharmacy (AMCP) submission guidelines [11] reference the International Society for Pharmacoeconomics and Outcomes Research (ISPOR) guidelines [12]. In the USA health care system, BIA could be important in determining the tier (co-payment and coinsurance) on a private insurer's formulary or could be used to negotiate discount rates.

\section{Issues and challenges of BIA use}

Although the use of BIA is completely different in the four countries, it does present common methodological issues and faces similar challenges.

The methodological issues are about the extent to which BIA should take into account the complexity of the disease/ condition under study: its treatment (modelling of acute or chronic treatments, taking into account treatment switching and treatment sequences) and patient behaviour patterns. For instance, the recent review of US BIA [13] and the new BIA guideline developed by the HAS [4] have pointed out further areas for development of methods estimating the budget impact of a new technology.

Today, combining long-term perspectives on the value of a new intervention through CEA with its short-term financial impact is far from being resolved. Linking CEA and BIA remains a challenge. Some analysts believe that the threshold value for the CEA should take care of any budget issues [14]. The threshold value represents opportunity costs at the margin and, therefore, reflects affordability at the margin. However, in the case of expensive innovative interventions, when a new intervention has a very large budget impact [e.g. the newest hepatitis $\mathrm{C}$ virus (HCV) drugs], then the opportunity cost is likely to be greater than the threshold value, assuming that budgets are fixed. Two crucial questions arise: should we keep budget impact and value assessments separate? And how can we implement a pragmatic use of BIA, reconciling consideration of the long-term care value of a new intervention and its potential short-term financial impact. The approach recently proposed by the Institute for Clinical and Economic Review (ICER) [13], a not-for-profit US organisation, addresses these issues, although it is not grounded in formal methodology. Broadly speaking, it tries to link budget impact to affordability by assuming that there is only a given percentage increase of budgetary 'headroom' when adopting new technologies, based on the likely growth in the economy. In this respect, ICER argued that "if the potential budget impact of a new intervention would contribute to an increase in overall health care costs at a rate greater than growth in the overall economy, health system value would be diminished" [15].

Therefore, a main consequence of linking budget impact and value assessment is that the budgetary implications are considered to be one of the factors that should influence the price paid for the new technology. That is, a high budgetary impact becomes a reason for reducing the price, either directly or indirectly by lowering the cost-effectiveness threshold. On the other hand, if the budget impact assessment is kept separate, it merely informs the decision maker about the size of the financial adjustments that would be necessary to adopt the new technology. These adjustments could include a reduction in the price of the new technology, but could also include disinvestments in other technologies and raising additional funds. In the context of publicly funded health care systems this would involve an increase in funding from government. In the context of privately funded systems it would involve an increase in premiums or patient co-payments. Therefore, keeping the budgetary impact separate gives more options, but also more responsibility, to the decision maker to deal with the final consequences of adoption of the new therapy. Either way, it would be important for the decision maker to identify the opportunity costs of adopting the new technology. 


\section{Conclusions}

The role of budget impact analysis is increasingly recognized in the whole process of reimbursement decision and price negotiation of new medicines among the four countries. The current guidelines available for budget impact analysis should improve the quality and the transparency of BIAs submitted by manufacturers. Today, there is a need to enhance the use of BIA, given the need for financial sustainability in health care. The relationships between the value of the new intervention (clinical and/or economic), its potential financial impact and opportunity costs in the short term and the equity concerns for health care access should be investigated theoretically and empirically by HTA agencies, public authorities and academic researchers.

Acknowledgments The authors would like to thank Prof. Mike Drummond for his useful comments and suggestions. The opinions expressed in this editorial are those of the authors and do not necessarily represent the views of their affiliated institutions.

\section{References}

1. Mauskopf, J.: Prevalence-based economic evaluation. Value Health 1(4), 251-259 (1998)

2. Trueman, P., Drummond, M., Hutton, J.: Developing guidance for budget impact analysis. Pharmacoeconomics 19(6), 609-621 (2001)

3. Ghabri, S., Hamers, F.F., Josselin, J.M.: Exploring uncertainty in economic evaluations of drugs and medical devices: lessons from the first review of manufacturers' submissions to the French National Authority for Health. Pharmacoeconomics 34(6), 617624 (2016). doi:10.1007/s40273-016-0381-4

4. Haute Autorité de Santé (HAS). Guide méthodologique: choix méthodologiques pour l'analyse de l'impact budgétaire à la HAS. http://www.has-sante.fr/portail/upload/docs/application/ pdf/201612/guide_methodologique__choix_methodologiques_ pour_lanalyse_de_limpact_budgetaire_a_la_has_.pdf (2017). Accessed 11 Oct 2017

5. Ghabri, S., Pouillé, A.I., Autin, E., Josselin, J.M.: Le guide d'analyse d'impact budgétaire de la HAS: un nouvel outil d'aide à la décision. Santé Publique 29(4), 585-588 (2017)
6. Pharmaceutical Benefits Advisory Committee (PBAC). Department of Health, Australian Government. Guidelines for preparing submissions to the pharmaceutical benefits advisory committee. Canberra (AU): Commonwealth of Australia. http://www.pbac. pbs.gov.au/content/information/printable-files/pbacg-book.pdf (2013). Accessed 20 Sept 2017

7. DHA-Australian Government. Department of Health and Ageing. Annual Report 2010-2011. Available at: http://www. health.gov.au/internet/main/publishing.nsf/Content/annualreport2010-11 (2011). Accessed 15 Sept 2017

8. Mauskopf, J., Chirila, C., Masaquel, C., et al.: Relationship between financial impact and coverage of drugs in Australia. Int. J. Technol. Assess. Health Care 29(1), 92-100 (2013)

9. National Institute for Health and Care Excellence (NICE). Assessing resource impact methods guide. Manchester. http://www.nice. org.uk/Media/Default/About/what-we-do/Into-practice/costing/ ria-method-guide-revision-V12-consultation.pdf (2015). Accessed 11 Oct 2017

10. National Institute for Health and Care Excellence (NICE). Single technology appraisal: user guide for company evidence submission template. London. http://www.nice.org.uk/article/pmg24/ chapter/instructions\%20for\%20companies (2015). Accessed 11 Oct 2017

11. Academy of Managed Care Pharmacy (AMCP). The AMCP format for formulary submissions. A format of submission of clinical and economic evidence of pharmaceuticals in support of formulary consideration. Alexandria. http://amcp.org/practice-resources/amcp-format-formulary-submisions.pdf (2012). Accessed 11 Oct 2017

12. International Society for Pharmacoeconomics and Outcomes Research, Sullivan, S.D., Mauskopf, J.A., Augustovski, F., Jaime Caro, J., Lee, K.M., et al.: Budget impact analysis—principles of good practice: report of the ISPOR 2012 Budget Impact Analysis Good Practice II Task Force. Value Health 17(1), 5-14 (2014)

13. Mauskopf, J., Earnshaw, S.: A methodological review of US budget-impact models for new drugs. Pharmacoeconomics 34, 1111-1131 (2016)

14. Claxton, K., Martin, S., Soares, M., et al.: Methods for the estimation of the National Institute for Health and Care Excellence cost-effectiveness threshold. Health Technol. Assess. 19, 1-503 (2015)

15. Institute for Clinical and Economic Review (ICER). Evaluating the value of new drugs and devices. http://icer-review.org/wpcontent/uploads/2014/01/Slides-on-value-framework-for-nationalwebinar1.pdf. Accessed 11 Oct 2017 